This item was submitted to Loughborough's Research Repository by the author.

Items in Figshare are protected by copyright, with all rights reserved, unless otherwise indicated.

\title{
Preventing bullying in school and work contexts
}

PLEASE CITE THE PUBLISHED VERSION

http://dx.doi.org/10.1093/acrefore/9780190264079.013.14

PUBLISHER

Oxford University Press

VERSION

AM (Accepted Manuscript)

PUBLISHER STATEMENT

COYNE, I.J. and CAMPBELL, M., 2017. Preventing bullying in school and work contexts. IN: Pontell, H.N. (ed.) Oxford Research Encyclopedia of Criminology and Criminal Justice, Oxford: OUP, pp. 1 - 64 reproduced by permission of Oxford University Press, http://dx.doi.org/10.1093/acrefore/9780190264079.013.14.

\section{LICENCE}

All Rights Reserved

\section{REPOSITORY RECORD}

Coyne, lain, and Marilyn Campbell. 2019. "Preventing Bullying in School and Work Contexts". figshare. https://hdl.handle.net/2134/26240. 
Preventing bullying in School and Work Contexts

$$
\text { Iain Coyne }{ }^{1} \text {, Marilyn Campbell }{ }^{2}
$$

${ }^{1}$ School of Business and Economics, Loughborough University, UK

${ }^{2}$ School of Early Childhood and Inclusive Education, Queensland University of Technology,

Australia 


\section{Summary}

The knowledge-base on bullying within school and working contexts has matured to the extent that researchers and practitioners are developing a deeper understanding of this complex social relationship problem. Although controversies still exist, evidence to date provides estimates of the prevalence of bullying, risk factors for bullying, antecedents of bullying and theoretical models explaining bullying behavior and experience. There is little doubt that bullying in all its forms can have severe negative impacts on those involved in the bullying situation. As a result, it is important to establish coherent and evidence-based approaches to preventing bullying behavior in schools and workplaces.

In contrast, the development and evaluation of bullying interventions has not received the same level of support. Both in school and working contexts, there are examples of preventative approaches, but these are either espoused and not directly evaluated, or, where evaluations exist, data is limited in providing definitive answers to the success of an approach. An increasingly dominant voice advocates the creation of policies and laws for preventing workplace bullying. However, the usefulness of policies and laws on their own in reducing bullying is questionable especially if they are developed with a quick-fix mentality. Trying to prevent such a complex social phenomenon requires an integrated, program of actions necessitating significant investment over a prolonged period of time. Stakeholder engagement is paramount to any intervention. Ultimately, schools and workplaces need to try and develop a culture of dignity, fairness, respect and conflict management which pervades throughout the institution. Challenges remain on how to create such interventions, whether they are effective and the impact societal values will have on the success of bullying prevention strategies. 
Keywords: School bullying, workplace bullying, bullying interventions, policy, legislation 


\section{Preventing bullying in School and Work Contexts}

Bullying is a complex social relationship issue which impacts detrimentally on the individuals involved, the organizations/schools they inhabit, and the wider community. The majority of people will be aware of bullying from their involvement as a victim or perpetrator, as having witnessed the behavior or from exposure to media reports about this phenomenon (Monks \& Coyne, 2011). It is recognized both in research and practice as a major concern and one in which various stakeholders need to take action.

The increasing academic publications on bullying and the advanced methodological approaches to research have created a wealth of information to expand our understanding of this complex issue. In comparison to this enhanced knowledge-base, evidence on the development and evaluation of preventative approaches is limited. This essay, focusing on school and workplace bullying, synthesizes the research literature on bullying interventions and provides a critical debate of the rationale and effectiveness of current approaches. Commencing with school bullying, the role of the media, law, policy, school climate, preventative programs and management of bullying is analyzed. Next, workplace bullying approaches framed within a primary, secondary and tertiary categorization are critiqued, specifically concerning risk assessment, training, rehabilitation, policy, legislation and bystanders. The effectiveness of interventions is then assessed followed by some good practice guidelines. The essay culminates in a discussion of the main issues and implications for bullying intervention going forward.

\section{School bullying}

Researchers define school bullying as "being an aggressive, intentional act or behavior that is carried out by a group or an individual repeatedly over time against a victim who cannot easily defend him or herself” (Smith et al., 2008). This definition was premised on Dan Olweus' 
original conception that bullying is a subset of aggression with three main pillars: the intention of the perpetrator to hurt; the behavior is repeated; and there is a power imbalance in the relationship. However, these pillars have been debated for many decades with some researchers for example questioning the notion of repetition (Naylor, Cowie, \& Cossin, 2006).

Historically, school bullying was conceptualized as including physical and verbal acts, with social/exclusion bullying being recognized later in the 1990’s (Spears, Slee, Owens, \& Johnson, 2009). At the beginning of the century another form was added, cyberbullying. This was not about recognition of a form of bullying but rather, with the advances of technology, a new form. However, there has been vigorous debate over the last 10 years as to whether cyberbullying is bullying or another form of aggression (Dooley, Pyżalsk, \& Cross, 2009). Indeed, it has been shown that all these forms of bullying substantially overlap (Cross et al., 2009). The implication is that no matter what form bullying takes, prevention efforts need to focus on all and not regard preventing cyberbullying just by technological means but address it as part of the relationship problem which is bullying. As shown later, prevention programs addressing traditional bullying also reduce cyberbullying.

Involvement with bullying in any form in any role usually has negative consequences, both short and long term. Students who are victimized have been shown to have internalizing problems such as anxiety and depression (Campbell, Spears, Slee, Butler, \& Kift, 2012), decreased self-esteem (Chang et al., 2013), peer problems (Dooley et al., 2012), greater loneliness (Nansel, Craig, Overpeck, Salvia, \& Ruan, 2001) and substance abuse problems (Mitchell, Ybarra, \& Finkelhor, 2007). Longitudinal studies have reported that childhood bullying victimization is predictive of poor mental health outcomes (Copeland, Wolke, Angold, 
\& Costello, 2013) and poor educational and occupational outcomes (Holt et al., 2014; Wolke, Copeland, Angold, \& Costello, 2013).

Students who bully others also have problems with anxiety and depression (Campbell, et al., 2012) and high levels of stress (Cross et al., 2009) and students who are bully-victims have been shown to experience even more serious negative outcomes than either students who bully others or those who are victimized (Unnever, 2005).

The prevention of school bullying is a difficult but necessary task to reduce the serious negative consequences for all students involved in this behavior. While there are many calls for prevention strategies to address bullying in schools and many research studies which evaluate the strategies, there is not as yet a comprehensive, definite answer on the best way to accomplish this. This is because bullying is an extremely complex social relationship problem which is deeply embedded in society.

\section{Prevention of bullying in schools}

A useful framework for understanding the complexity of bullying is Bronfenbrenner's Ecological Systems theory (1979). Bronfenbrenner conceptualized a child's environment as a multi-layered set of interconnected environmental systems, which all influence the development of the child. The theory posits five systems whose influence may be proximal and direct or distal and indirect. These are the micro - (e.g., parents, family), meso - (e.g., school), exo - (e.g., the wider community), macro - (e.g., media) and chrono - systems (e.g., historical events). From this socio-ecological perspective bullying is seen as a complex relationship issue that involves individual characteristics of students who are involved which are influenced by a variety of contexts (Hong \& Espelage, 2012). Bullying prevention involves all levels of the ecological system (Rigby \& Johnson, 2016). 
In prevention literature, there are three levels; primary, secondary and tertiary. Primary prevention is similar to universal intervention in that all students are targeted. It is estimated that primary prevention programs will be successful with about $80 \%$ of students to reduce bullying (Espelage \& Swearer, 2008). Fifteen percent of students will need extra secondary prevention strategies and programs or targeted intervention while the remaining $5 \%$ will need tertiary strategies.

Taking Bronfenbrenner's model from the more distal perspective of the whole of society and combining this with a primary prevention approach, there are two influences which could be brought to bear on the prevention of bullying in schools; the mass media, and the law will be discussed from the macro-system. The exo-system will discussed in terms of anti-bullying policies with school climate at the meso or school level. This level will also involve the microsystems of the family and include secondary and tertiary prevention strategies.

\section{Media}

Mass media is influential in shaping society's views about political and societal issues (Scheufele \& Tewksbury, 2007). That is, the media influences what people think about; the agenda setting theory (McCombs \& Shaw, 1972). Agenda setting is about the salience of an issue and originates from the field of political communication. It is the process whereby the mass media shapes the "public's policy priorities by leading the public to view certain issues as more important” than other issues (Lomax Cook et al., 1993, p.16).

Bullying is portrayed mainly in the print media and has alerted the public to the changing status of bullying from a fundamental and inescapable feature of childhood (Limber \& Small, 2003), to a behavior of substantial concern, since research has shown the negative consequences of being involved in bullying (Barnes et al., 2012). The newest form of bullying, cyberbullying, 
has attracted much media attention in many countries (Vandebosch, Simulioniene, Marczak, Vermeulen, \& Bonetti, 2013). Public knowledge about bullying is therefore guided by contemporary journalism, which often then guides policy development, funding, and legislature. It is important therefore to understand how the news media influences particular ways of thinking about bullying to develop prevention strategies to reduce it.

The media also contributes to how people view a social issue; that is, framing. Framing states "that how an issue is characterized in news reports can have an influence on how it is understood by audiences” (Scheufele \& Tewksbury, 2007, p. 11-12). Framing can be traced back to psychology. It refers to how journalists reconstruct a story from a certain angle. Quality news media mostly frame thematically, focusing on topics abstractly and looking at general causes of social problems such as bullying while popular media frames episodically focusing on individual events and looking at specific causes (Manssens \& Walgrave, 1998). Bullying is often framed as sensationalist bullicide which helps to sell newspapers (Walton 2005). The invention of the word "bullicide" for students who have mental health problems and complete suicide is an example of the alarmist attitude that is conveyed to adults by the media (Hinduja \& Patchin, 2010).

Bullying is thus framed to induce moral panic, which is when an issue becomes defined as a threat to society's values and interests and is then portrayed in stereotyped fashion and experts provide solutions (Kupiers, 2006). In this way media influence could be seen as exacerbating the problem with young people when bullied believe that suicide is an option and the increase in students who cyberbully by telling victims to kill themselves. Moral panics “decontextualize particular events and legitimate punitive discourse and policies” (Schissel, 1997, p. 15) 
Thus get tough measures, zero-tolerance policies, are implemented which could have harmful unintended consequences such as labelling a student a bully who then lives up to the name (Yeager et al., 2014). While the media can be beneficial in raising awareness of bullying, sometimes the sensationalism could lead to policy makers and law makers making policies and laws which have harmful unintended consequences for students.

\section{The law}

Every society has a form of law to govern the actions of its members. In considering the law as a prevention or intervention strategy for bullying, the purposes for which the law can be used, needs to be examined. First, most people think the law exists to provide clear rules to punish behavior that is judged to be wrong. This forms the criminal justice system. There are difficulties however, in applying criminal law to children and bullying behavior. All bullying is not of a severe enough nature to warrant criminal action. It would also be difficult to prove beyond reasonable doubt that a student was socially excluded and/or was constantly called names. In addition, children under a certain age (usually about ten years-old) are unable to be held criminally liable.

The second purpose of the law is to deter unwanted behavior by fear of the aforementioned punishments. There are difficulties again in using the criminal legal system for this purpose with young people and bullying. Young people are impulsive and often would not consider if what they were doing was unlawful. Moreover, the criminal laws against underage sexual relations and graffiti have not had the deterrent effect the public expect. Bullying behavior in schools is also often difficult to detect, so the surveillance to make a case to prosecute would be almost impossible (Campbell \& Zavrsnik, 2013). 
Third, the law can be used for compensation. The victim of bullying could seek retribution from a bully or seek criminal injuries compensation (Butler, Kift, \& Campbell, 2009). However, civil law would usually be invoked with the parents of students suing schools for damages as most students would not have the money for compensation.

Fourth, the law can be enacted as a social norm, reflecting society’s morals and values (Vago, 2009). However, the law and social norms impact each other so the law can also influence social norms and values in society (Evan, 1965). Not only can the law compel students to change their behavior by punishment, it can also influence their views on what is right and wrong (Droback, 2006). Legislation might also not need to be enforced but still conveys an educative message “symbolically announcing what society deems good and valuable” (Limber \& Small, 2003, p. 448). Lastly the law can mandate school policy. Anti-bullying policies for schools are legally required for schools in England (Samara \& Smith, 2008) and in many states in America (Surdin, 2009). The effectiveness of anti-bullying school policies will be discussed in the next section.

So why look to the law to prevent bullying? It is interesting to note that there have been no public calls for laws on bullying in schools until this century when the new form of cyberbullying emerged. This could be because of the media attention cyberbullying has generated or that today's adult does not fully understand the digital age and is more afraid of it than face-to-face bullying which they knew about in their own childhood. In the litigious nation of the USA, especially following the first high school shootings in the 1990's many states have enacted legislation to make bullying a crime or a misdemeanor (Snakenbourg, 2011). However, as King has argued, the most effective way to prevent bullying is in classrooms not in courtrooms (King, 2010). 
It is still surprising though that more action is not called for in prevention efforts at this broad level in society using both the media and the law, as bullying is deeply embedded in our communities not started anew by each generation of children at school. As Walton (2005) says “bullying is a manifestation of larger power relations in society” (p. 113) but most prevention efforts are directed to children in schools.

\section{Policy as prevention}

As mentioned previously in many countries it is mandatory for schools to have an antibullying policy. In 2002 Ananiadou and Smith canvassed European Union countries and found that the UK, Finland, Sweden, France, Malta and Ireland had mandated anti-bullying policies. Since then at least Austria, Belgium and Denmark have added anti-bullying policies on their education websites. In the United States of America almost all states require school policies which conform to that state’s anti-bullying laws (Cornell \& Limber, 2014). In Canada similarly, most provinces have safe school frameworks which address bullying (Roberge, 2011). Australia was one of the first countries in 2003 to develop a national policy for the prevention and management of bullying in schools. The National Safe Schools Framework was endorsed by all state ministers in 2010 so that schools are encouraged to develop proactive policies against bullying and to regularly review and evaluate their policies (Cross et al., 2011).

The purpose of anti-bullying policies is to ensure that guidelines are written so that a school's prevention and management of bullying is transparent, known to all stakeholders and consistently applied so that bullying is reduced. A policy shows the commitment of the school to address bullying, raise awareness of bullying and set an expected code of behavior. However, although it seems eminently sensible to have an anti-bullying policy there is scant evidence that these polices per se make a difference in reducing bullying in schools. Evaluation of policies is 
important not only to ensure there is a reduction in bullying but also that the policies have no unintended harmful consequences and they are not wasting resources and time (American Psychological Association, 2008).

To assess the preventative effects of anti-bullying policies, the outcome is reduced bullying after the policy has been implemented. One of the first studies was conducted in England in 1998 where it was found in 25 secondary schools there was less than a ten percent reduction of bullying incidents in schools with a policy compared to those without policies (Glover, Cartwright, Gough, \& Johnson, 1998). Again in England in 2003, Woods and Wolke examined 34 anti-bullying policies in primary schools. They found no correlation between the quality and the content of the policies and prevalence of student bullying behavior. In fact, the schools with the most detailed policies reported more social/exclusion bullying. In South Wales a large survey of 26000 students aged 11-16 years found less perpetration and victimization reported by students in schools with clear rules about bullying (Lambert et al., 2008). However, the rules were not as predictive as gender and socio-economic status in explaining the reduction in bullying. Similarly, Smith et al. (2012) found no correlation between the quality of school anti-bullying policies and student bullying.

Few studies have been conducted in the United States and those which have, have been seriously flawed. For example, Hatzenbuehler and colleagues (2015) conducted an analysis of 25 state laws (policies) on bullying and linked them with individual student level data on bullying. They found reduced odds ratio of students reporting bullying when the policies were more detailed. However, the level of the analysis was at state and not school level and there was no prior data of the prevalence of student bullying in any of the states before the policies were 
introduced. In Australia, researchers have found no decrease or no change in student bullying after policy implementation (Cross et al., 2011; Soutter \& McKenzie, 2000).

This evidence is concerning when most prevention strategies for bullying rely on antibullying policies as a vital strategy. However, there could be many reasons why these policies do not seem to be effective in reducing bullying. First, how the policy is created is of major importance. It has been shown that ownership of a policy by the whole school community leads to more effective implementation (Smith, Ananiadou, \& Cowie, 2003). Schools which copy another school's policy or use institutionalized formatting instead of involving all stakeholders, students, parents and school staff will probably not implement such a policy effectively. Second, the content of anti-bullying policies is important. Definitions need to be clear and precise yet understandable and able to be applied (Cornell \& Limber, 2015). Accuracy of the definition is important to ensure students experience equitable consequences and staff are protected from being accused of unfairness when enacting the policy. Prevention measures should be one of the first strategies in anti-bullying policies however, it has been found that reactive measures are more common (Woods \& Wolke, 2003). A policy also needs to be educative and developmentally appropriate which sees bullying perpetration as behavior to be rectified. The content of the policy also needs to include how students will respond to any bullying. A policy, as can be seen, is not a simple document. However, if the policy is not disseminated then it cannot be effective.

While implementation seems essential, it has been found that only $47.8 \%$ of students in 25 Australian schools in Years 5-10 were aware that their school had such a policy (Rigby \& Johnson, 2016). Additionally, if the policy is not implemented by school staff it cannot be effective. How teachers respond to reports of bullying will determine whether students will 
report to them (Cortes \& Kochenderfer-Ladd, 2014). Thus to create and implement anti-bullying policies to prevent bullying in schools is a complex and difficult task. If any of the steps are not carried out, from creation and accurate content to dissemination and implementation, then the policy will not be effective. For the creation and implementation of an anti-bullying policy there needs to be a collegial community of practice, communicating with all stakeholders, showing mutual respect with a common purpose (Richard, 2011). It is unsurprising therefore, that if there is this positive school climate then the policy would be effective. However, as a prevention for bullying in a school it is precisely that positive school climate that needs to be developed.

\section{Improving school climate as prevention}

School climate is an important correlate of bullying behaviors but is a complex, multidimensional, nebulous term which is difficult to precisely measure. School climate has been defined "as the collective beliefs, values, and attitudes that prevail at a school and are (re) produced through social interactions between students, teachers and other school staff” (Laftman, Ostberg, \& Modin, 2017, p. 155). Some studies measure only one facet of school climate such as relationships among students (Bacchini, Esposito, \& Affuso, 2009) or provide data from only one informant. Other studies have measured composite facets surveying students, teachers and parents (Saarento et al., 2015).

Numerous studies have found a correlation between aspects of school climate and the prevalence of bullying. A positive school climate where students are treated with respect, where they believe school is a good place to be and felt rules were fair, predicted less perpetration and victimization (Guerra, Williams, \& Sadek, 2011; Gregory et al. 2010; Khoury- Kassabri, Benbenishty, Avi Astor, \& Zeira, 2004). Normative beliefs among students that bullying is acceptable is associated with more perpetration (Gendron, Williams, \& Guerra, 2011) whereas 
where students perceive their teachers have a disapproving attitude towards bullying there is less peer victimization (Saarento et al., 2013).

This correlation between a positive school climate and less bullying is not surprising. Bullying is a social relationship problem and a major component of school climate is a culture of connectedness, of acceptance, and support (Kub \& Feldman, 2015). In fact, it could be said that it borders on a circular argument that if a school has good relations between students and good relations between students and teachers then axiomatically this means there would be less negative relationships, such as bullying.

What is beneficial however, in striving to create a positive school climate for the prevention of bullying is that there is the possibility of change which is not as daunting as producing change in society as a whole. As the two key elements of a positive school culture are favorable relationships among students and teachers and negative attitudes to bullying (Wang, Berry, \& Swearer, 2013) then promoting and modelling appropriate behaviors and attitudes by the adults in the school is a crucial first step. However, there are many other considerations in having a positive school climate such as parent-school engagement, leadership and mental health programs. School climate might be a necessary but not sufficient condition to reduce bullying.

\section{Programs as prevention}

The most widely used and researched prevention strategy for bullying is prevention programs delivered in schools. These are usually designed by researchers and often evaluated by the same people who created them. Some successful programs are Friendly Schools Plus Program and Cyber Friendly Schools by Donna Cross and colleagues (Cross et al., 2011; 2016) and KiVa by Christina Salmivalli (Garandeau, Poskiparta, \& Salmivalli, 2014). The increasing emphasis on only implementing evidenced-based programs, while good practice, makes it 
difficult for schools to obtain affordable and practical programs (Holt, Raczynskil, Frey, Hymel, \& Limber, 2013). These stand-alone programs are usually at the primary level of prevention of teaching pro-social skills, awareness of bullying and encouraging bystanders to intervene to support the student being victimized and/or to stop the bullying (Bradshaw, 2015).

Unfortunately, several meta-analyses have shown that school-wide bullying prevention programs have had negligible to non-significant results in reducing bullying (Merrell, Gueldner, Ross, \& Isava, 2008). By contrast, Farrington and Ttofi's (2011) meta-analysis of 44 studies found that anti-bullying programs reduced bullying behavior by $20-30 \%$ and victimization by 17 $23 \%$.

There are numerous reasons advanced for the variation in effectiveness of these programs from differences in fidelity and dosage to the school's ability to implement the programs school wide (Olweus \& Limber, 2010). Teachers are often asked to implement these programs and yet there is scant pre-service teacher preparation in this area (Spears et al., 2015) or in-service provision for practicing teachers (Bauman \& Del Rio, 2006) to ensure appropriate teacher attitudes to bullying and the realization that these programs cannot be changed to suit their situation. Not only do teachers need to have good relationships with their students but they also need to involve parents, especially those students who need secondary prevention strategies who are involved in bullying (Lovegrove, Bellmore, Green, Jens, \& Ostrov, 2013).

Tertiary prevention programs are rare in bullying in schools; that is targeting students who persistently bully. One program is the Bullying Intervention Program (BIP; Swearer \& Givens, 2006) an individual cognitive-behavioral program for students who bully others. Another project is trialing motivational interviewing, a cognitive counselling technique, which has been successfully used to reduce drug use, eating disorders and violent behavior in 
adolescents (Frey et al., 2011; Hettema, Steele, \& Miller, 2005). The interviewing seeks to find out the motivations behind a student's behavior and direct them to other more socially acceptable means to achieve these goals. It is hypothesized that the high dose intervention schools will have significantly lower rates of bullying perpetration and victimization as reported by school staff and students.

A cautionary note has been made by Yeager, Fong, Lee and Espelage (2015) on the declines in efficacy of anti-bullying programs as students become older. This meta-analysis showed that while bullying can be prevented in children who are in Year 7 or below, there was no effect in students in Year 8. In fact there seems such a reversal in efficacy in secondary schools that the authors concluded the programs could be harmful.

\section{Management of bullying incidents}

The management of bullying incidents in schools could be seen to be either a secondary or tertiary approach to prevention. Punitive approaches to addressing students who bully others are limited (O’Moore, 2010; Rigby \& Bauman, 2009) and are often the least successful way of reducing bullying (Thompson \& Smith, 2011). Restorative approaches and rehabilitative measures may be more effective in dealing with bullying (Cowie \& Jennifer, 2007). However, in a comprehensive examination of guidelines to prevent bullying, it was found there was little encouragement to assist students who persistently bully to learn new ways to behave (O’Moore, 2010). The management of bullying needs to provide opportunities for students to learn prosocial behaviors to have their needs met (Chin, Dowdy, Jimerson, \& Rime, 2012). 


\section{Workplace bullying}

Bullying at work has been defined as:

‘...harassing, offending, socially excluding someone or negatively affecting someone's work tasks. In order for the label bullying (or mobbing) to be applied to a particular activity, interaction or process it has to occur repeatedly and regularly (e.g. weekly) and over a period of time (e.g. about six months). Bullying is an escalating process in the course of which the person confronted ends up in an inferior position and becomes the target of systematic negative social acts. A conflict cannot be called bullying if the incident is an isolated event or if two parties of approximately equal 'strength'are in conflict' (Einarsen, Hoel, Zapf \& Cooper, 2003, p. 15).

While there are ongoing differences of opinion of how bullying is conceptualized, labelled and measured (Coyne, 2011), similar to school bullying, consensus among researchers posits criteria of frequency, persistence and power imbalance as key defining features of this phenomenon (e.g., Keashly \& Harvey, 2005; Zapf \& Einarsen, 2001). For a critical debate on understanding and assessing workplace bullying, readers should consult Herschcovis (2011).

Comparative to the research history into school bullying, systematic investigation into workplace bullying is a relatively recent phenomenon (Coyne, 2011). However, through adopting multi-method, cross-disciplinary and cross-cultural perspectives, research and practitioner understanding of workplace bullying has evolved rapidly to a state of increasing awareness of how bullying develops and the impact of bullying on individuals and organizations.

With increasing knowledge of the area comes a growing understanding of how to tackle bullying - its causes and its consequences. The current section focuses on interventions for managing workplace bullying by considering the organizational context for bullying interventions, followed by a critical overview of suggested actions framed within primary, 
secondary and tertiary stages. Policy and legislative approaches are then debated and evidence to date for the effectiveness of interventions is highlighted. The debate culminates in a brief discussion of the role of bystanders in bullying intervention and some practical recommendations.

\section{The context for workplace bullying interventions}

Initially two questions should be considered in relation to the context for bullying interventions. These questions allow researchers and practitioners to gauge the potential success of interventions in organizations as well as current practice. The questions are:

- What are organizations currently doing to prevent bullying?

- What is the 'attitude' of organizations to workplace bullying interventions?

National surveys help provide information to answer the first question. Data illustrates 55\% of UK managers (Woodman \& Cook, 2005) and 56\% of Finnish public sector HR managers (Salin, 2008) stated their organizations introduced anti-bullying policies. Specifically, Salin noted $66 \%$ of the Finnish organizations surveyed provided information on bullying; $27 \%$ offered bullying training and 25\% reported bullying cases as statistically recorded. Updating the 2005 survey, Woodman and Kumar (2008) show 74\% of UK managers surveyed reported their organization adopted an anti-bullying policy (an increase of 19\% from 2005). While a promising development, their data illustrated only $40 \%$ of managers had received specific training on workplace bullying and 35\% perceived their organizations ineffective at deterring bullying.

Survey data may also offer an insight into organizational attitudes to workplace bullying intervention, as a piecemeal approach to policy creation, training and data recording suggests limited buy-in to workplace bullying prevention. Additionally, others authors (Ferris, 2004; Rayner \& McIvor, 2008) advocate a typology of organizational approaches to intervention as a 
means of judging responsiveness to workplace bullying. They argue approaches to tackling bullying range from those taking a proactive stance, acknowledging bullying is harmful and developing a policy coupled with training and counselling; to those where bullying is endemic, normalized and not taken seriously.

Resch and Schubinski (1996) pose some reasons why anti-bullying programs are not universal:

1. Anti-bullying interventions are in competition with other (perceived more important) interventions which may show better return on investment.

2. The pressure on organizations to develop bullying interventions is not as strong as it is for other interventions (especially those required by law).

3. Developing bullying interventions may portray a negative image of the organization as one with a problem of bullying.

It is within this context that researchers and practitioners need to educate organizations and advocate appropriate, evidence-based, solutions to preventing workplace bullying. However, it should be borne in mind that an organization's attitude to tackling bullying may inhibit the adoption, the choice and success of a specific intervention.

\section{Stages of bullying intervention}

How do we go about developing a workplace bullying intervention plan and what will it look like? Clearly, consultation of empirical investigations and theoretical models will provide initial idea generation. In particular, the weight placed on organizational explanations for workplace bullying such as role conflict (Notelaers, De Witte, \& Einarsen, 2010), poor leadership (Hoel, Glasø, Hetland, Cooper, \& Einarsen, 2010), stressful environments (Hauge, Skogstad, \& Einarsen, 2007), politicized environments (Salin, 2003) and organizational change 
(Skogstad, Matthiesen, \& Einarsen, 2007) highlight routes for intervention development.

Similarly, theoretical models explaining workplace bullying as a result of fairness perceptions (Parzefall \& Salin, 2010) and job demands/resources (Baillien et al., 2011) can be used to guide preventative solutions. However, there is still need for a framework in which this evidence can be subsumed and which offers practical, evidence-based solutions.

Similar to the school context, many researchers have advocated a three-stage framework focused on prevention, intervention and rehabilitation for the development of workplace bullying interventions (Hershcovis, Reich, \& Niven, 2015; Hubert, 2003; Rayner \& McIvor, 2008; Vartia \& Leka, 2011). Coyne (2011) further adds a levels-perspective mapping organizational, group and individual antecedents of workplace bullying. He also identifies a higher society level capturing the impact of society values, laws, unions, professional bodies, Governments and charities. Unanimously, researchers and practitioners agree that prevention is the best approach, although there is acknowledgement of other actions which need to be taken should bullying continue.

Primary interventions. Primary stage interventions are geared towards preventing bullying through an evidence-based consideration of the risk factors promoting bullying (Hershcovis et al., Rayner \& Cooper, 2006; Vartia \& Leka, 2011). As a result, these interventions are proactive in nature and designed to reduce the risks of bullying occurring in the first place. At an organizational level, clear policy development which details the organization's stance on bullying and aims to change employee attitudes to workplace bullying is a minimal requirement (Hubert, 2003; Richards \& Daley, 2003). Later on, more discussion will be offered around bullying policies, yet suffice it to say bullying policies if developed and implemented correctly should foster a culture of dignity and respect at work (Rayner \& McIvor, 2008). 
A risk management perspective views bullying as a psycho-social hazard and requires (Spurgeon, 2003):

- hazard identification;

- $\quad$ assessment of the risk;

- $\quad$ preventative strategies.

Hazard identification typically culminates in a shared understanding of what the hazard is and its characteristics. However, as previously outlined, no one agreed definition of bullying currently exists with different labels such as 'mobbing' (Zapf \& Einarsen, 2001) ‘workplace harassment’ (Brodsky, 1976), ‘abusive supervision’ (Tepper, 2000), ‘victimization’ (Aquino \& Bradfield, 2000), ‘emotional abuse’' (Keashly \& Harvey, 2005); ‘workplace incivility’ (Pearson, Andersson \& Porath, 2005) and 'social undermining' (Crossley, 2009) used to conceptualize bullying at work. Indeed, while there is some agreement that bullying involves frequency, duration and a power imbalance, critics raise questions on whether these criteria should be adhered to rigidly (Rayner \& Cooper, 2006) and if similar perspectives are viewed by different stakeholders (Saunders, Huynh, \& Goodman-Delahunty, 2007).

Potentially, organizations are left with a paradox. To implement a risk management intervention approach, the hazard (bullying) needs defining, but if an agreed definition is lacking organizations either cannot implement an effective prevention plan or may be developing an approach addressing the wrong behavior. Arguably, this is more of a conceptual debate than a practical one, because in reality an intervention targeted at preventing any form of interpersonal abusive behavior is likely to reduce the risks of bullying from occurring - especially, if the aim of the intervention is to develop a culture within the workplace of dignity and respect. 
Assuming hazard identification has been achieved, Spurgeon (2003) states the level of risk from bullying should be measured. This can include collating data on numbers of individuals involved and the impact for individuals and the organization of bullying. Unequivocal empirical evidence for the effects workplace bullying can have on targets, witnesses and organizations supports the notion of bullying being harmful (see Coyne, 2011 for a review). Additionally, within the research literature surveys establishing the prevalence of experiencing workplace bullying in different countries are abundant. Data indicates rates of $10.6 \%$ in the UK (Hoel, Cooper \& Faragher, 2001); 28\% in the US (Lutgen-Sandvik, Tracey \& Alberts, 2007); 8.8\% in Finland (Salin, 2001) and 8\% in Denmark (Mikkelsen \& Einarsen, 2002). Meta-analytical research of 86 studies points to a mean prevalence rate of experiencing bullying of $14.6 \%$ (Nielsen et al., 2010). Critically, methodological approaches have been questioned within survey studies (Cowie, Naylor, Rivers, Smith \& Pereira, 2002) and moderators identified (Nielsen, Matthiesen \& Einarsen, 2010) which temper our ability to establish definitive bullying rates in the workplace.

If an organization navigates successfully the maze of hazard definition and risk assessment, it can then implement preventative strategies related to organizational antecedents of workplace bullying. These include changes to work design (linked to reducing stressors and frustrations), to leadership (through training) and raising the moral culture in the workplace (Resch \& Schubinski, 1996).

While not as advanced as organizational-level approaches, group level primary interventions concentrate on changing group norms and values via a program of awareness training and the development of group norms against bullying (Hubert, 2003). It is important to recognize and consider the group level in any preventative strategy as groups may create in- 
groups and out-groups in which they direct their aggression towards those in an outsider role (LaVan \& Martin, 2008) and hence a less powerful position (Einarsen et al., 2003). Vartia, Korppoo, Fallenius \& Mattila (2003) advocates a role for Occupational Health Services at this level in helping to mediate group conflict via group meetings to try and obtain a sense of how the group deals with conflict.

Due to the focus on organizational level explanations for workplace bullying and subsequent interventions addressing these antecedents, consideration of preventative strategies aimed at individual stakeholders is limited. Advocates of the organizational antecedent viewpoint subscribe to the idea that individual-level interventions are not effective (PRIMA EF, 2008). However, research points to individual factors pre-disposing an employee to become a target of bullying (Aquino, Grover, Bradfield \& Allen, 1999; Coyne, Seigne \& Randall, 2000) and bullies are reported to be violent (Leather, Cox \& Farnsworth, 1990), tyrannical (Ashforth, 1994) and aggressive (Seigne, Coyne, Randall \& Parker, 2007). It is naïve to think individual differences do not have some influence on bullying at work, especially if one considers not everyone in the same environment will be a target or a bully. Therefore, individual-level interventions around training in emotional regulation, empathy, social skills and assertiveness could help prevent the vulnerability of potential targets as well as the aggressiveness of the perpetrator.

Secondary interventions. Unlike the proactive nature of primary interventions, secondary interventions are reactive and aimed at providing employees who have experienced bullying with coping skills (Vartia \& Leka, 2011). Training in coping, managing emotions and reappraising the aggression (Hershcovis et al., 2015) attempt to either change the way an individual (usually targets but this could easily be applied to perpetrators) behaves in response to bullying behaviors or his/her perceptions of bullying-type behaviors. Previously, individual 
antecedents of bullying were outlined to illustrate possible evidence for individual-level preventative strategies. This literature can also be used to support the need for target/perpetrator training interventions as individual differences could help explain how people cope with bullying, react to bullying and view aggressive behaviors.

Additionally at this level, organizations should create formal grievance policies that deal with bullying cases (Rayner \& McIvor, 2008) and informal 'buddy' or dignity advisor networks for those experiencing bullying to contact and seek advice (Resch \& Schubinski, 1996).

However, secondary bullying interventions focused on individual training are controversial because they are seen as removing the responsibility for controlling bullying away from organizations towards individual employees (Spurgeon, 2003). Additionally, a lack of empirical evidence as to the effectiveness of secondary interventions inhibits their applicability within practice.

More promisingly, Vartia and Leka (2011) promote the notion of adopting conflict escalation models to guide the nature and timing of interventions after bullying has commenced. Organizational climate for conflict management has been shown to relate negatively to bullying experience and positive to work engagement (Einarsen, Skogstad, Rørvik, Lande \& Nielsen, 2016). This research suggests environments where perceived conflicts are handled well tend to experience reduced levels of perceived bullying. In their contingency model of conflict however, Keashly and Nowell (2011) caution against the use of a single intervention approach at all levels of conflict. They argue that interventions need to be coordinated and comprehensive, beginning with an understanding of the history and current status of the bullying. As a result, the most effective intervention to adopt is contingent on the stage of conflict escalation (Table 1).

Insert Table 1 about here 
Tertiary interventions. The focus at this stage is on reducing the negative impact of bullying on individuals and organizations as well as rehabilitating victims back into the workplace. Tehrani (2012) promotes a five-stage integrated counselling approach to dealing with workplace bullying:

1. Assessment -involves the counsellor undertaking a full psychological assessment of the individual to establish the nature of the distress; a description of how the counselling session will run; and discussion on what the individual would like to achieve from counselling.

2. Education - provides the individual with information on the processes of stress from a biological and psychological perspective as well as feedback on psychological assessments completed within the previous stage.

3. Symptom reduction - based on initial assessments, specific activities aimed at reducing symptoms are discussed with the individual. These may include relaxation techniques, lifestyle changes or desensitization.

4. Integration and understanding - here the individual learns how to reflect on his/her responses to bullying episodes. Awareness of thoughts, feelings and actions of these episodes is enhanced and often recorded via journals. As a result the individual can see their changing perceptions/emotions over time.

5. Rehabilitation - support is needed to facilitate an individual's return to the original workplace or working life more generally. Visualization allows the individual to reflect on potential issues that may arise and therefore seek support. Further, Tehrani (2003) argues that it is important to offer counselling to the perpetrator (e.g. appropriate behavior) to aid his/her rehabilitation back into the workplace. 
Counselling may offer a route for an individual to reduce the anxiety and distress of experiencing bullying and rehabilitate the individual back into working life. Nevertheless, counselling is not appropriate for all contexts (especially if a victim is experiencing extreme traumatic stress) and should be viewed as part of an intervention package (Tehrani, 2012).

\section{Policy as prevention}

Anti-bullying policies as a preventative approach to managing workplace bullying has already been considered and it is evident that such policies are dominant in this area (Beale \& Hoel, 2011; Woodman \& Kumar, 2008). The aims of anti-bullying policies are to identify clearly what bullying is and which behaviors are unacceptable; to promote a culture of dignity and respect; and to identify the process (e.g. documentation, procedure and people) an individual should adopt if feel they have been bullied at work. Practically, Richards and Daley (2003) detail a step-by-step approach to effective policy development, implementation and monitoring:

1. Initial data collection to allow for a better understanding of the bullying problem (if one exists).

2. Create a representative working group involving relevant stakeholders (e.g. managers, supervisors, employees, unions, outside facilitator) who participate in developing the initial draft policy. Involvement and participation by a range of stakeholders promotes a message of organizational commitment to addressing bullying and ownership of the policy.

3. Populate the policy with a number of features. These should include a definition of what bullying is; a declaration that bullying will not be tolerated within the organization; specification of various roles and duties in implementing the policy (e.g., managers, unions); identification of dignity at work advisors who can offer 
support and guidance; description of the formal complaints/grievance procedure and how it operates in terms of process, timing, fairness and confidentiality; and promotion of required training for managers and employees on the policy.

4. Monitor the effectiveness of the policy. However, the authors argue that monitoring is not implemented consistently and needs improvement.

The ethos of bullying at work policies and ubiquitous nature implies effectiveness. However, Beale and Hoel (2011) suggest limitations to the effectiveness of a policy methodology. They argue that bullying policies are often focused on litigation rather than promoting dignity at work, they discourage collective action (via unions) and promote individual action, and managers may not wish to enforce a policy in their department/organization - especially if they are implicated in the perceived bullying. Advancing this, in-depth interviews of UKbased Human Resource (HR) practitioners indicated the role of trust in a policy and its implementation (Harrington, Rayner, \& Warren, 2012). Themes emerged of distrust between the HR practitioner and employee (where HR practitioners, resulting from previous experience, become skeptical of bullying claims from employees), distrust between HR practitioners and managers (to protect the HR-manager relationship, cases would only be discussed with the manager if there was a solid basis) and distrust in a HR practitioner's enactment of an anti-bullying policy (e.g., a perception that HR practitioners repackage bullying as inappropriate management).

Evidently, while policies are the dominant intervention approach, to ensure their effectiveness they need to have senior level endorsement, involve a number of stakeholders in their development, promote a culture of dignity and identify a clear informal/formal 
procedure in which employees have trust. It is not sufficient to draft a policy which espouses such a process, but in practice in not adhered to correctly in all cases.

\section{The law}

Realistically, discussions of bullying interventions cannot proceed without some debate on the legal framework surrounding bullying at work. Questions should be considered on whether bullying is illegal and to what extent are laws adopted? Trying to answer these questions is problematic as globally, countries have different legal frameworks for bullying - indeed even within countries there are differences at state or province level. Therefore, this debate will consider the legal perspective generally, outlining what the law is trying to achieve and the approaches adopted globally.

As already detailed in the section on school bullying the law can act as a method to punish or deter people, as a deterrent to engaging in what is a criminal act, as a way of obtaining damages and compensation, as a method for formalizing society norms and as an obligation to develop organizational policies. Related to managing bullying, these outcomes map well onto the primary (prevent/deter), secondary (punishment) and tertiary (compensation) stages of intervention.

Internationally, a number of approaches have been adopted from a legal perspective (Yamada, 2011). These include: specific amendments to existing health and safety laws; recognition of bullying within statutory law; enactment of harassment law; voluntary policies which create legal obligations; and international recognition of bullying from policy-making organizations. Yamada (2011) also describes differing legal approaches within Australia, Canada, France, Sweden, the UK and USA. 
Akin to the debate on policies, creation and promotion of a legal framework around bullying at work 'may' be welcomed, yet their effectiveness as preventing bullying at work is perhaps the more important issue to address. For example, Bukspan (2004) reports sector differences in the implementation of the Law for Social Modernisation in France. Specifically, she noted that guarantees detailed within the law offered to private sector employees are not afforded to public sector employees. Additionally, authors have outlined a number of challenges to creating bullying legislation (Campbell \& Završnik, 2013). Firstly, criminal law requires a clear definition of the actual crime and given the disagreements around how bullying is defined, it is difficult to advocate one specific definition which is either agreed by all or which captures the concept fully. As a result, an individual who is accused of workplace bullying may not be deemed to be engaging in a criminal act if the behavior(s) do/does not map accurately on to the legal definition. Secondly, and related to the first challenge, confusion in defining bullying or the omission of a bullying definition completely may result in reluctance by law enforcement agencies to act - particularly where finite resources need to be allocated elsewhere. Thirdly, especially for cyberbullying, the global nature to the bullying may cause issues in how to collect appropriate evidence and which country’s legal framework should be used to prosecute a perpetrator.

In conclusion, although pressures for the creation/adoption of specific bullying laws will continue to mount, it is difficult to conceptualize how such a law will work at national and international levels (e.g. multinational organizations). Arguably, existing laws/framework in many countries can be enacted for bullying and the creation of a law which captures all the nuances of workplace bullying is not achievable. The legal approach may also promote policy development as a means to ensure compliance with a law rather than developing a culture of 
dignity and respect. Therefore, the law may only have a small role (if any) to play in preventing workplace bullying and more focus should be on educating employees about creating a culture of dignity and respect.

\section{Effectiveness of bullying interventions}

Evaluation of bullying interventions is essential as it helps to establish if the particular approach is effective and provides learning opportunities for future practice (Hodgins, MacCurtain, \& Mannix-McNamara, 2014). Spurgeon (2003) suggests evaluation should focus on whether procedures are in place to address bullying, evidence that procedures are working, and the success of the system in reducing bullying at work. Surprisingly, systematic empirical research into workplace bullying interventions is sparse and where evidence exists conclusions are mixed.

Hoel and Giga (2006) report on the effectiveness of a six-month bullying intervention implemented within five UK public sector organizations. Their approach included policy communication, stress awareness training (e.g., how to deal effectively with stress) and negative behavior awareness training (e.g., impact of behavior on others). Counter to what might be hoped for; data indicated a slight rise in bullying from pre to post intervention from $13.6 \%$ to $14.3 \%$. Mikkelsen, Hogh and Olesen (2008) provide preliminary results on a two-year intervention study within three Danish organizations. Through a process of increasing awareness of bullying and developing employee/manager/organizational competences in conflict management, positive results emerged for only one organization. However, the authors do suggest that effectiveness was moderated by the extent that managers prioritize and participate in the intervention. LeónPérez, Arenas and Griggs (2012) assessed the effectiveness of conflict management training via participant reactions after training, participant learning two weeks after training and post- 
intervention measures eight months after training. Findings illustrated positive reactions towards the usefulness of the training, an increase in perceived knowledge of conflict management, a reduction in interpersonal conflicts at work post training and a small reduction in experienced negative acts. However, the authors caution that the lack of a control group and the potential for sampling error moderate the robustness of these results.

Despite directed towards civility rather than workplace bullying, Osatuke, Moore, Ward, Dyrenforth \& Belton (2009) present initial evaluative data on a Civility, Respect and Engagement in the Workforce (CREW) initiative in the US. Across 23 sites, commitment towards a program of regular work-group discussions on civility was required which helped to foster group understanding of the situation as well as plan interventions tailored to work-group needs. In comparison to matched (non-intervention) samples mean ratings of civility were significantly increased for intervention samples from pre to post intervention. Extending the CREW intervention to cover assessment of incivility, distress, attitudes and physical stress; Leiter, Day, Oore, and Laschinger (2012) examine its effectiveness within Canadian health care providers (in comparison to controls) immediately after the intervention and one year later. Improvements in ratings of civility, incivility, distress and job attitudes were seen immediately after training and one year later. Differences in the pattern of the effect suggested a continued improvement in ratings of civility, incivility and distress after the end of the intervention; whereas for job attitudes increases were sustained after intervention but did not continue improving.

Hodgins, MacCurtain, and McNamara (2014) systematically reviewed the evidence for workplace bullying and incivility interventions. From the 12 studies reviewed, four addressed organizational antecedents, two focused on behavior change and six were directed towards 
knowledge change. Only two were related to theory and just three could actually be assessed in terms of effectiveness - the others having weak study designs. While these three were either judged partially or fully effective, they were only focused on incivility and not workplace bullying.

Clearly more systematic research is needed which adopts stronger methodological designs and which focuses directly on workplace bullying. It is a sobering thought that all the advances made in understanding workplace bullying, especially the antecedents and theoretical explanations, have barely, to date, been transferred adequately to effective bullying interventions.

\section{The role of bystanders}

Bystanders witness bullying but are not involved directly as either a bully or target. To date, research on bystanders in workplace bullying is limited (Paull, Omari \& Standen, 2012), even though bystanders are the largest group affected by workplace bullying (Lutgen-Sandvik, 2006). However, bystanders may be important because they can react immediately to bullying acts and co-workers are more likely to confide in them (Scully \& Rowe, 2009) as well as discourage or escalate the bullying behaviours by speaking up on the victim's behalf or support the bully either actively or passively ( Bloch, 2012; Lutgen-Sandvik, 2006).

Consequently, approaches to managing workplace bullying that stimulate positive and inhibit negative bystander actions should be included. Bystanders are a focal group in interventions to control workplace bullying as they outnumber targets, perpetrators and supervisors and can be a catalyst for the continuation or reduction of bullying. Coyne et al. (2016) suggest organizations should build into existing processes, procedures in which bystanders feel safe in reporting behavior. Scully and Rowe (2009) specify an active bystander toolkit involving practicing a number of scenarios where approaches to intervention are 
illustrated. Going forward, there is a need to develop training packages directed at bystander behavior and well as evaluation of this training.

\section{Good practice recommendations for preventing workplace bullying}

In debating critically the area of workplace bullying prevention, evidence points to a general understanding of actions based on the extant research which should be implemented, but limited information on their evaluation and effectiveness. Clearly, there is scope for developing evidence-based, effective anti-bullying interventions and, although a number of alternative routes have been detailed in this discussion, an appropriate starting point could be consideration of good practice in bullying interventions. To conclude this section on workplace bullying interventions and synthesizing opinions from a number of researchers (Hershcovis et al., 2015; Rayner \& Cooper, 2006; Vartia \& Leka, 2011) a set of practical recommendations can be offered:

1. Center the intervention on evidence in relation to assessing the risks of antecedents of bullying.

2. Detail clearly behaviors deemed appropriate and inappropriate and ensure all relevant stakeholders understand what is/is not tolerated within the workplace.

3. Create systems and procedures to allow targets and bystanders to report bullying and how the organization will deal with cases of bullying at a formal/informal level. This can be captured by a policy, but policies need to be enacted appropriately when required.

4. Provide awareness training for all stakeholders of the organizational approach to bullying and the procedure in investigating bullying. 
5. Provide individual level training that develops manager's competencies in detecting bullying and conflict management as well as helping individuals deal with workplace stress and cope better.

6. Consider mediation early on in a conflict process, but be cognizant that as conflicts escalate mediation is unlikely to be useful and other forms of intervention will need to be considered.

7. Ensure all stakeholders have ownership of the intervention and buy into its ethos.

8. Provide counselling and support to targets and perpetrators to help rehabilitate back into work.

9. At intervention development phase, detail the evaluation plan for the intervention. Focus on short, medium and long-term objectives and ways this data is collected to allow for robust conclusions to be made.

\section{Overall conclusions}

The extant literature on school and workplace bullying discussed here provides some guidance and ideas on how to prevent this severe abusive relationship behavior. Patently, more research on and evaluation of strategies to prevent bullying is needed, especially in what contexts, under what circumstances and for whom. The diversity of ideas and the relative lack of substantial evidence supporting existing interventions attest to the need for clarity in how to prevent bullying and consistency in how we evaluate bullying interventions. In reality, effective bullying prevention strategies are the missing piece in the bullying research jigsaw.

However, a number of points can be gleamed from the debate presented. Firstly, researchers/practitioners should steer themselves away from trying to develop approaches specific to forms of bullying or aggression. Prevention efforts should focus on abusive behavior 
more generally, which in turn are likely to prevent bullying specifically. Secondly, researchers need to establish or agree on a framework on which to base bullying prevention strategies. In this essay, the primary, secondary and tertiary model as well as Bronfenbrenner's model were highlighted as the foundations on which to build interventions. In actual fact, a hierarchical model subsuming primary, secondary and tertiary interventions within an environmental systems framework may provide the much needed clarity to move forward with developing and evaluation bullying interventions. Such a model would be capable of being used across not only school and working contexts, but other contexts where bullying may occur. Thirdly, albeit advocated by an increasingly vocal group (e.g., media, parents, unions etc.), policy creation and legislative approaches on their own are not sufficient to prevent bullying and may result in unintended negative consequences for those involved within the bullying process. Often they go hand-in-hand as policy is created in response to new laws. However, the ethos here is one of preventing an organization or individual from legal consequences and not prevention of bullying within schools or the workplace. It promotes a minimum action philosophy and tick-box attitude that is likely to reduce trust in policy implementation. Creation of effective policies requires resources, engagement by various stakeholders, clear communication, description of formal/informal procedures and regular monitoring/evaluation. Fourthly, imperative in any prevention strategy is the need to establish a positive climate that fosters mutual respect, dignity and fairness. This may well begin with policy development, yet it will need to be enhanced with culture change programs, conflict management approaches and modelling of appropriate behaviors. As alluded to previously, this approach will require significant investment in time and resources and involve a number of actions over a prolonged period of time. Whether schools and 
organizations are able or willing to invest in such an approach remains to be seen. However, without such investment, it is debatable whether bullying will be successfully reduced.

One caveat to establishing bullying prevention strategies is the impact of society. Societal norms, values and pressures effectively create a national/international climate within which local school and organization climates reside. Society-level interventions have not been considered extensively, yet societal norms implicitly promoting unacceptable interpersonal behavior are likely to be modelled by individuals and acted out at school or work. This leaves us with a dilemma. If, the creation of climates promoting respect, dignity and fairness are the way forward, how can this culture embed itself within institutions when the dominant societal norms is exclusion, competition and unfairness. Therefore, referring back to Bronfenbrenner's model, society as a whole needs to play a role in addressing bullying in any form, from workplace bullying to domestic violence, alongside specific contextual interventions. 


\section{Further reading}

\section{School context}

Bradshaw, C. P. (2015). Translating research to practice in bullying prevention programs. American Psychologist, 70, 4, 322-332.

Coloroso, B. (2002). The bully, the bullied, and the bystander: From pre-school to high school, how parents and teachers can help break the cycle of violence. Toronto: HarperCollins.

Espelage, D. L. (2016). Leveraging school-based research to inform bullying prevention and policy. American Psychologist, 71, 768-775. doi: 10.1037/amp0000095

Monk, C. P., \& Coyne, I. (2011). Bullying in different contexts. Cambridge: Cambridge University Press.

Saarento, S., Garandeau, C. F., \& Salmivalli, C. (2015). Classroom- and school-level contributions to bullying and victimization: A review. Journal of Community and Applied Social Psychology, 25, 204-218.

Smith, P. K., \& Steffgen, G. (Eds.), Cyberbullying through the new media: Findings from an international network. London: Psychology Press.

Ttofi, M. M., \& Farrington, D. P. (2011). Effectiveness of school-based programs to reduce bullying: A systematic and analytic review. Journal of Experimental Criminology, 7, 2756. doi: 10.1007/s11292-010-9109-1

Yeager, D. S., Fong, C. J., Lee, H., \& Espelage, D. (2015). Declines in efficacy of anti-bullying programs among older adolescents: A developmental theory and a three-level metaanalysis. Journal of Applied Developmental Psychology, 37, 36-51. doi: 10.1016/j.appdev.2014.11.005 


\section{Work context}

Coyne, I. J (2011). Bullying in the workplace. In C. M. Monks and I. Coyne (Eds.), Bullying in different contexts (pp. 157-184). Cambridge: Cambridge University Press.

Einarsen, S., Hoel, H., Zapf, D., \& Cooper, C. (2011). Bullying and harassment in the workplace: Developments in theory, research, and practice ( $2^{\text {nd }}$ Edition). Boca Raton, FL: CRC Press.

Hershcovis, M. S. (2011). 'Incivility, social undermining, bullying ... oh my!': A call to reconcile constructs within workplace aggression research. Journal of Organizational Behavior, 32, 499-519.

Hershcovis, S. M., Reich, T. C., \& Niven, K. (2015). Workplace bullying: Causes, consequences, and intervention strategies. SIOP White Paper Series. Bowling Green, OH: SIOP.

Leiter, M. P., Day, A., Oore, D. G., Laschinger, H. K. S. (2012). Getting better and staying better: Assessing civility, incivility, distress, and job attitudes one year after a civility intervention. Journal of Occupational Health Psychology, 17, 425-434.

Osatuke, K., Moore, S. C., Ward, C. Dyrenforth, S. R., \& Belton, L. (2009). Civility, respect, engagement in the workforce (CREW). Nationwide organizational development intervention at veterans health administration. The Journal of Applied Behavioral Science, 45, 384-410. 


\section{Links to digital materials}

ACAS policy discussion paper (http://www.acas.org.uk/media/pdf/e/b/Seeking-better-solutionstackling-bullying-and-ill-treatment-in-Britains-workplaces.pdf).

Workplace Bullying Institute in the US (http://www.workplacebullying.org/).

David Yamada YouTube clip (https://www.youtube.com/watch?v=EorTZHnukDU).

UK Government guide (https://www.gov.uk/workplace-bullying-and-harassment).

Fair Work Commission in Australia (https://www.fwc.gov.au/disputes-at-work/anti-bullying)

You Tube clip on employees use of the Fair Work Act in Australia

(https://www.youtube.com/watch?v=KEWe1WspU3Q). 


\section{References}

American Psychological Association Zero Tolerance Task Force (2008). Are zero tolerance policies effective in schools? American Psychologist, 63, 852-862. doi:10.1037/0003066X.63.9.852.

Ananiadou, K., \& Smith, P.K. (2002). Legal requirements and nationally circulated materials against school bullying in European countries. Criminal Justice, 2, 471-491. doi: 10.1177/17488958020020040501

Aquino, K., Grover, S. L., Bradfield, M., \& Allen, D. G. (1999). The effects of negative affectivity, hierarchical status, and self-determination on workplace victimization. Academy of Management Journal, 42, 260-272. DOI: 10.2307/256918.

Aquino, K., \& Bradfield, M. (2000). Perceived victimization in the workplace: The role of situational factors and victim characteristics. Organization Science, 11, 525-537. http://dx.doi.org/10.1287/orsc.11.5.525.15205.

Archer, J., \& Coyne, S. M. (2005). An integrated review of indirect, relational, and social aggression. Personality and Social Psychology Review, 9, 212-230.

doi:10.1207/s15327957pspr0903_2

Ashforth, B. (1994). Petty tyranny in organizations. Human Relations, 47, 755-770. DOI: https://doi.org/10.1177/001872679404700701

Bacchini, D., Esposito, G., \& Affuso, G. (2009). Social experience and school bullying. Journal of Community and Applied Social Psychology, 19, 17-32. doi:10.1002/casp.975

Baillien, E., Rodriguez-Muñoz, A., Van den Broeck, A., \& De Witte, H. (2011). Do demands and resources affect target's and perpetrators' reports of workplace bullying? A two-wave cross-lagged study, Work \& Stress, 25, 128-146.

http://dx.doi.org/10.1080/02678373.2011.591600 
Barnes, A., Cross, D., Lester, L., Hearn, L., Epstein, M., \& Monks, H. (2012). The invisibility of covert bullying among students: Challenges for school intervention. Australian Journal of Guidance and Counselling, 22, 206-266. doi:10.1017/jgc.2012.27

Beale, D., \& Hoel, H. (2011). Workplace bullying and the employment relationship: Exploring questions of prevention, control and context. Work, Employment \& Society, 25, 5-18. DOI: $10.1177 / 0950017010389228$.

Berkowitz, L. (1993). Aggression: Its causes, consequences and control. New York: McGraw-Hill.

Bloch, C. (2012). How witnesses contribute to bullying in the workplace. In N. Tehrani (Ed.), Workplace Bullying, (pp. 81-96). East Sussex: Routledge.

Bond, L., Wolfe, S., Tollit, M., Butler, H., \& Patton, G. (2007). A comparison of the Gatehouse Bullying Scale and the Peer Relations Questionnaire for students in secondary school. Journal of School Health, 77(2), 75-79. doi:10.1111/j.1746-1561.2007.00170.x

Bradshaw, C. P. (2015). Translating research to practice in bullying prevention programs. American Psychologist, 70, 4, 322-332.

Bradshaw, C. P., Waasdorp, T. E., \& Johnson, S. L. (2015). Overlapping verbal, relational, physical, and electronic forms of bullying in adolescence: Influence of school context. Journal of Clinical Child and Adolescent Psychology, 44, 494-508. doi: $10.1080 / 15374416.2014 .893516$

Brodsky, C. M. (1976). The Harassed Worker. Toronto: Lexington Books, D. Heath and Company.

Bronfenbrenner, U. (1979). The ecology of human development: Experiments by nature and design. Cambridge, MA: Harvard University Press. 
Bukspan, E. (2004). Bullying at work in France. British Journal of Guidance and Counselling, 32, 397-406. DOI: 10.1080/03069880410001723585

Butler, D., Kift, S., \& Campbell, M.A. (2009). Cyber bullying in schools and the law: Is there an effective means of addressing the power imbalance? eLaw Journal: Murdoch Electronic Journal of Law, 16, 84-114.

Butler, D., Kift, S., Campbell, M. A., Slee, P., \& Spears, B. (2011). School policy responses to cyberbullying: An Australian legal perspective. International Journal of Law and Education, 16, 7-28.

Campbell, M. A. \& Zavrsnik, A. (2013). Should cyberbullying be criminalized? In P. K. Smith \& G. Steffgen (Eds.), Cyberbullying through the new media: Findings from an international network (pp. 65-82). London: Psychology Press.

Campbell, M.A., Spears, B., Slee, P., Butler, D., \& Kift, S. (2012). Victims’ perceptions of traditional and cyberbullying, and the psychosocial correlates of their victimisation. Emotional and Behavioural Difficulties, 17, 389-401. doi: $10.1080 / 13632752.2012 .704316$

Chang, F. C., Lee, C. M., Chiu, C. H., Hsi, W. Y., Huang, T. F., \& Pan, Y. C. (2013). Relationships among cyberbullying, school bullying, and mental health in Taiwanese adolescents. Journal of School Health, 83, 454-462.

Chin, J., Dowdy, E., Jimerson, S., \& Rime, W. (2012). Alternatives to suspensions: Rationale and recommendations. Journal of School Violence, 11, 156-173. doi:

$10.1080 / 15388220.2012 .652912$ 
Chen, L. M., Liu, K. S., \& Cheng, Y. Y. (2012). Validation of the perceived school bullying severity scale. Educational Psychology, 32, 169-182. doi:10.1080/01443410.2011.633495.

Copeland, W., Wolke, D., Angold, A., \& Costello, E. (2013). Adult psychiatric outcomes of bullying and being bullied by peers in childhood and adolescence. JAMA Psychiatry, 70, 419-426. doi: 10.1001/jamapsychiatry.203.504

Cornell, D., \& Limber, S. (2015). Law and policy on the concept of bullying at school. American Psychologist, 70, 333-343. doi:10.1037/a0038558

Compton, L., Campbell, M. A., \& Mergler, A. G. (2014). Teacher, parent and student perceptions of the motives of cyberbullies. Social Psychology of Education, 17, 383-400.

Cowie, H., Naylor, P., Rivers, I., Smith, P. K., \& Pereira, B. (2002). Measuring workplace bullying. Aggression and Violent Behavior, 7: 33-51. http://dx.doi.org/10.1016/S13591789(00)00034-3.

Cowie, H., \& Jennifer, D. (2007). Managing violence in schools: A whole-school approach to best practice. London: Paul Chapman.

Coyne, I. (2011). Bullying in the workplace. In C. P. Monks, \& I. Coyne (Eds.), Bullying in Different Contexts, (pp. 157-184). Cambridge: Cambridge University Press

Coyne, I., Seigne, E., \& Randall, P. (2000). Predicting workplace victim status from personality. European Journal of Work and Organizational Psychology, 9, 335-349. DOI: $10.1080 / 135943200417957$.

Coyne, I., Farley, S., Axtell, C., Sprigg, C., Best, L \& Kwok, O. (2016). Workplace cyberbullying, employee mental strain and job satisfaction: A dysempowerment 
perspective. International Journal of Human Resource Management, published online ahead of print 26th Feb 2016, 1-28. http://dx.doi.org/10.1080/09585192.2015.1116454.

Craig, W. M., Henderson, K., \& Murphy, J. (2000). Prospective teachers’ attitudes towards bullying and victimization. School Psychology International, 21, 5-21. doi:10.1177/0143034300211001

Cross, D., Shaw, T., Hearn, L., Epstein, M., Monks, H., Lester, L., \& Thomas, L. (2009). Australian covert bullying prevalence study. Perth, Western Australia: Child Health Promotion Research Centre, Edith Cowan University.

Cross, D., Monks, H., Hall, M., Shaw, T., Pintabona, Y., Lester, L. (2011). Three-year results of the friendly schools whole-of-school intervention on children's bullying behavior. British Educational Research Journal, 37, 105-129. doi: 10.1080/01411920903420024

Cross, D., Shaw, T., Hadwen, K., Cardoso, P., Slee, P., Roberts, C., ... Barnes, A. (2016). Longitudinal impact of the Cyber Friendly schools program on adolescents’ cyberbullying behavior. Aggressive Behavior, 42, 166-180. doi: 10.1002/ab.21609

Crossley, C., D. (2009). Emotional and behavioral reactions to social undermining: A closer look at perceived offender motives. Organizational Behavior and Human Decision Processes, 108, 14-24. DOI:10.1016/j.obhdp.2008.06.001

Dehue, F., Bolman, C., Vollink, T., \& Pouwelse, M. (2012). Cyberbullying and traditional bullying in relation with adolescents’ perceptions of parenting. Journal of CyberTherapy and Rehabilitation, 5, 25-34.

Dooley, J.J., Pyżalsk, J., \& Cross, D. (2009). Cyberbullying versus face-to-face bullying. Zeitschrift für Psychologie/Journal of Psychology, 217(4), 182-188. doi: 10.1027/00443409.217.4.182

Droback, J. N. (2006). Norms and the law. Cambridge: Cambridge University Press. 
Due, P., Merlo, J., Harel-Fisch, Y., Damsgaard, M. T., Soc, M. S., Holstein, B. E., \& de Matos, M. G. (2009). Socioeconomic inequality in exposure to bullying during adolescence: A comparative, cross-sectional, multilevel study in 35 countries. American Journal of Public Health, 99, 907-914. doi:10.2105/AJPH.2008.139303.

Einarsen, S., Hoel, H., Zapf, D., \& Cooper, C. L. (2003). The concept of bullying at work: the European tradition. In S. Einarsen, H. Hoel, D. Zapf, and C. L. Cooper (Eds.), Bullying and emotional abuse in the workplace. International perspectives in research and practice (pp. 3-30). London, UK: Taylor and Francis.

Einarsen, S., Skogstad, A., Rørvik, E., Lande, A. B., \& Nielsen, M. B. (2016). Climate for conflict management, exposure to workplace bullying and work engagement: a moderated mediation analysis. The International Journal of Human Resource Management. DOI: 10.1080/09585192.2016.1164216.

Evan, W. M. (1965). Law as an instrument of social change. In A. W. Gouldner \& S. M. Miller (Eds.), Applied sociology: Opportunities and problems (pp. 285-293). New York: Free Press.

Espelage, D. L., \& Swearer, S. M. (2008). Current perspectives on linking school bullying research to effective prevention strategies. In T. W. Miller (Ed.), School violence and primary prevention (pp. 335-353). New York: Springer.

Farrington, D., \& Ttofi, M. (2009). School-based programs to reduce bullying and victimization: A systematic review. Campbell Systematic Reviews, 5(6), 1-148.

Ferris, P. (2004). A preliminary typology of organisational response to allegations of workplace bullying: see no evil, hear no evil, speak no evil. British Journal of Guidance and Counselling, 32, 389-395. DOI: 10.1080/03069880410001723576. 
Frisen, A., Berne, S., Schultze-Krumbholz, A., Scheithauer, H., Naruskove, K....Zukauskiene, R. (2013). Measurement issues: A systematic review of cyberbullying instruments. In P. K. Smith \& G. Steffgen (2013). Cyberbullying through the new media: Findings from an international network (pp. 37-62). London: Psychology Press.

Frey, A.J., Cloud, R., Lee, J., Small, J., Seeley, J. ... Golly, A. (2011). The promise of motivational interviewing in school mental health. School Mental Health, 3(1), 1-12. doi:10.1007/s12310-010-9048-z

Garandeau, C. F., Poskiparta, E., \& Salmivalli, C. (2014). Tackling acute cases of school bullying in the KiVa anti-bullying program: A comparison of two approaches. Journal of Abnormal Child Psychology, 42, 981-991. doi:10.1007/s10802-014-9861-1

Gendron, B. P., Williams, K. R., \& Guerra, N. G. (2011). An analysis of bullying among students: Estimating the effects of individual normative beliefs, self-esteem, and school climate. Journal of School Violence, 10, 150-164. doi:10.1080/15388220.2010.539166

Gladden, R.M., Vivolo-Kantor, A.M., Hamburger, M.E., \& Lumpkin, C.D. (2014). Bullying surveillance among youths: Uniform definitions for public health and recommended data elements, Version 1.0. Atlanta, GA; National Center for Injury Prevention and Control, Centers for Disease Control and Prevention and U.S. Department of Education.

Glover, D., Cartwright, N., Gough, G., \& Johnson, M. (1998). The introduction of anti-bullying policies: Do policies help in the management of change? School Leadership and Management, 18(1), 89-105. doi:10.1080/13632439869790

Gregory, A., Cornell, D., Fan, X., Sharas, P., Shih, T.-H., \& Huang, F. (2010). Authoritative school discipline: High school practices associated with lower bullying and victimization. Journal of Educational Psychology, 102, 483-496. 10.1037/a0018562 
Guerra, N. G., Williams, K. R., \& Sadek, S. (2011). Understanding bullying and victimization in childhood and adolescence: A mixed methods study. Child Development, 82, 295-310. doi:10.1111/j.1467-8624.2010.01556.x

Harrington, S., Rayner, C., \& Warren, S. (2012). Too hot to handle? Trust and human resource practitioners' implementation of anti-bullying policy. Human Resource Management Journal, 22, 392-408. DOI: 10.1111/1748-8583.12004

Hatzenbuehler, M., Schwab-Reese, L., Ranapurwala, S., Hertz, M., \& Ramirez, M. (2015). Associations between antibullying policies and bullying in 25 states. JAMA Pediatrics, 169, 1-8. doi: 10.1001/jamapediatrics.2015.2411

Hauge, L. J., Skogstad, A., and Einarsen, S. (2007). Relationships between stressful work environments and bullying: Results of a large representative study. Work and Stress, 21, 220-242. DOI: 10.1080/02678370701705810.

Hemphill, S. A., Kotevski, A., Tollit, M., Smith, R., Herrenkohl, T. I., Toumbourou, J. W., \& Catalano, R. F. (2012). Longitudinal predictors of cyber and traditional bullying perpetration in Australian secondary school students. Journal of Adolescent Health, 51(1), 59-65. doi:10.1016/j.jadohealth.2011.11.019.

Hemphill, S.A., Heerde, J.A. \& Gomo, R. (2014). A conceptual definition of school-based bullying for the Australian research and academic community. Canberra: Australian Research Alliance for Children and Youth.

Hershcovis, M. S. (2011). “Incivility, social undermining, bullying... oh my!”: A call to reconcile constructs within workplace aggression research. Journal of Organizational Behavior, 32, 499-519. DOI: 10.1002/job.689. 
Hershcovis, S. M., Reich, T. C., \& Niven, K. (2015). Workplace bullying: Causes, consequences, and intervention strategies. SIOP White Paper Series. Bowling Green, OH: SIOP.

Hettema, J., Steele, J., \& Miller, W.R. (2005). Motivational interviewing. Annual Review of Clinical Psychology, 1, 91-111. doi:10.1146/annurev.clinpsy.1.102803.143833

Hinduja, S., \& Patchin, J. W. (2010). Bullying, cyberbullying, and suicidal ideation. Archives of Suicide Research, 14, 206-221. doi:10.1080/13811118.2010.494133

Hodgins, M., MacCurtain, S., \& Mannix-McNamara, P. (2014). Workplace bullying and incivility: a systematic review of interventions. International Journal of Workplace Health Management, 7, 54-72. DOI 10.1108/IJWHM-08-2013-0030.

Hoel, H., Cooper, C. L., \& Faragher, B. (2001). The experience of bullying in Great Britain: The impact of organizational status. European Journal of Work and Organizational Psychology, 10, 443-465. DOI:10.1080/13594320143000780.

Hoel, H., and Giga, S. I. (2006). Destructive Interpersonal Conflict in the workplace: The Effectiveness of Management Interventions. Manchester Business School: The University of Manchester.

Hoel, H., Glasø, L., Hetland, J., Cooper, C. L. \& Einarsen, S. (2010). Leadership styles as predictors of self-reported and observed workplace bullying. British Journal of Management, 21, 453-468. DOI: 10.1111/j.1467-8551.2009.00664.x.

Holt, M. K., Green, J. G., Reid, G., DiMeo, A., Espelage, D. ...Sharkey, J.D. (2014). Associations between past bullying experiences and psychosocial and academic functioning among college students. Journal of American College of Health, 62, 552-560. doi: 10.1080/07448481.2014.947990 
Holt, M., Raczynski, K., Frey, K., Hymel, S., \& Limber, S. (2013). School and community-based approaches for preventing bullying. Journal of School Violence, 12, 238-252. doi: $10.1080 / 15388220.2013 .792271$

Hong, J. S., \& Espelage, D. L. (2012). A review of research on bullying and peer victimization in school: An ecological system analysis. Aggression and Violent Behavior, 17, 311-322. doi:10.1016/j.avb.2012.03.003

Huang, F. L., \& Cornell, D. G. (2015). The impact of definition and question order on the prevalence of bullying victimization using student self-reports. Psychological Assessment, 27, 1484-1493. doi; 10.1037/pas0000149

Hubert, A. B. (2003). To prevent and overcome undesirable interaction: a systematic approach model. In S. Einarsen, H. Hoel, D. Zapf, \& C. L. Cooper (Eds.), Bullying and emotional abuse in the workplace. International perspectives in research and practice (pp. 299311). London, UK: Taylor and Francis.

Humphrey, G., \& Crisp, B. R. (2008). Bullying affects us too: Parental responses to bullying at kindergarten. Australian Journal of Early Childhood, 33(1), 45-49.

Karna, A., Voeten, M., Little, T. D., Poskiparta, E., Kaljonen, A., \& Salmivalli, C. (2011). A large-scale evaluation of the KiVa anti-bullying program: Grades 4-6. Child Development, 82, 311-330. doi: 10.1111/j.1467-8624.2010.01557.x

Karna, A., Voeten, M., Little, T. D., Alanen, E., Poskiparta, E., \& Salmivalli, C. (2013). Effectiveness of the KiVa antibullying program: Grades 1-3 and 7-9. Journal of Educational Psychology, 105, 535-551. doi:10.1037/a0030417 
Keashly, L., \& Harvey, S. (2005). Emotional abuse in the workplace. In S. Fox and P. E. Spector (Eds.), Counterproductive work behavior. Investigations of actors and targets (pp. 201235). Washington: American Psychological Association.

Keashly. L. \& Nowell, B. L. (2011). Conflict, conflict resolution and bullying. In S. Einarsen, H. Hoel, D. Zapf, \& C. L. Cooper (Eds.), Bullying and harassment in the workplace. Developments in theory, research and practice (pp. 423-446). Boca Raton, FL: CRC Press.

Khoury- Kassabri, M. Benbenishty, R., Avi Astor, R., \& Zeira, A. (2004). The contributors of community, family, school variables to student victimization. American Journal of Community Psychology, 34, 187-204. doi:10.1007/s10464-004-7414-4

King, A. V. (2010). Constitutionality of cyberbullying laws: Keeping the online playground safe both for teens and free speech. Vanderbilt Law Review, 63, 845-884.

Klomek, A. B., Marrocco, F., Kleinman, M., Schonfeld, I., \& Gould, M. (2007). Bullying, depression, and suicidality in adolescents. Journal of the American Academy of Child and Adolescent Psychiatry, 46, 40-49. doi:10.1097/01.chi.0000242237.84925.18

Kub, J., \& Feldman, M. A. (2015). Bullying prevention: A call for collaborative efforts between school nurses and school psychologists. Psychology in the Schools, 52, 658-671. doi:10.1002/pits.21853

Kupiers, G. (2006). The social construction of digital danger: Debating, defusing and inflating the moral dangers of online humor and pornography in the Netherlands and the United States. New Media \& Society, 8, 379-400. doi: 10.1177/1461444806061949 
Kumpulainen, K., Räsänen, E., \& Puura, K. (2001). Psychiatric disorders and the use of mental health services among children involved in bullying. Aggressive Behavior, 27, 102-110. doi:10.1002/ab.3

Laftman, S. B., Ostberg, V., \& Modin, B. (2017). School climate and exposure to bullying: A multi-level study. School Effectiveness and School Improvement, 28, 153-164. doi: 10.1080/09243453.2016.1253591

Langos, C. (2012). Cyberbullying: The challenge to define. Cyberpsychology, Behavior, and Social Networking, 15, 285-289. doi:10.1089/cyber.2011.0588

Lambert, P., Scourfield, J., Smalley, N., \& Jones, R. (2008). The social context of school bullying: Evidence from a survey of children in South Wales. Research Papers in Education, 23, 269-291. doi:10.1080/02671520701809866

LaVan, H., \& Martin, W. M. (2008). Bullying in the U.S. Workplace: Normative and ProcessOriented Ethical Approaches. Journal of Business Ethics, 83,147-165. DOI 10.1007/s10551-007-9608-9.

Le, T. H., Dunne, M. P., Campbell, M. A., Gatton, M. L., \& Nguyen, H. T. (2017). Temporal patterns and predictors of bullying roles among adolescents in Vietnam: A school-based cohort study. Psychology, Health \& Medicine. doi: 10.1080/13548506.2016.1271953

Leather, P. J., Cox, T., \& Farnsworth, W. J. F. (1990). Violence at work: An issue for the 1990s. Work and Stress, 4, 3-5. DOI: 10.1080/02678379008256959.

Leiter, M. P., Day, A., Oore, D. G., \& Laschinger, H. K. S. (2012). Getting better and staying better: Assessing civility, incivility, distress, and job attitudes one year after a civility intervention. Journal of Occupational Health Psychology, 17, 425-434. DOI: 10.1037/a0029540. 
Limber, S. P., \& Small, M. A. (2003). State laws and policies to address bullying in schools. School Psychology Review, 32, 445-455.

Leon-Perez, J. M., Arenas, A., \& Griggs, T. B. (2012). Effectiveness of conflict management training to prevent workplace bullying. In N. Tehrani, (Ed.), Workplace Bullying. Symptoms and Solutions (pp. 230-243). East Sussex: Routledge.

Lomax Cook, F., Tyler, T. R., Goetz, E. G., Gordon, M. T., Protess, D., Leff, D. A., \& Molotch, H. L. (1983). Media and agenda setting: Effects on the public, interest group leaders, policy makers, and policy. Public Opinion Quarterly, 47(3), 16-35. doi:10.1086/268764

Lovegrove, P., Bellmore, A., Green, J., Jens, K., \& Ostrov, J. (2013). “My voice is not going to be silent”: What can parents do about children's bullying? Journal of School Violence, 12, 253-267. doi: 10.1080/15388220.2013.792270

Lutgen-Sandvik, P. (2006). Take this job and...: Quitting and other forms of resistance to workplace bullying. Communication Monographs, 73, 406-433. DOI: 10.1080/03637750601024156

Lutgen-Sandvik, P., Tracy, S. J., \& Alberts, J. K. (2007). Burned by Bullying in the American Workplace: Prevalence, Perception, Degree and Impact. Journal of Management Studies, 44, 837-862. DOI: 10.1111/j.1467-6486.2007.00715.x.

Marr, N., \& Field, T. (2001). Bullycide, death at playtime: An expose of child suicide caused by bullying. Didcot, UK: Success Unlimited.

Manssens, J., \& Walgrave, S. (1998). Populair en/of kwaliteit? De Vlaamse pers over de zaakDutroux. [Popular and / or quality? The Flemish press about the Dutroux case] PSW papers. Anterwerpen: UIA.

Maunder, R., Harrop, A., \& Tattersall, A. (2010). Pupil and staff perceptions of bullying in secondary schools: Comparing behavioural definitions and their perceived seriousness. 
Educational Research, 52, 263-282. doi:10.1080/00131881.2010.504062

McCombs, M.E., \& Shaw, D.L. (1972). The agenda-setting function of mass media. Public Opinion Quarterly, 36(2), 176-187. doi: 10.1086/267990

Menesini, E., Nocentini, A., Palladino, B., Scheithauer, H., Schultz-Krumbholz, A. Blaya, C. (2013). Definitions of cyberbullying. P. K. Smith \& G. Steffgen (Eds.), Cyberbullying through the new media: Findings from an international network (pp. 23-36). London: Psychology Press.

Merrell, K. W., Gueldner, B. A., Ross, S. W., \& Isava, D. M. (2008). How effective are school bullying intervention programs? A meta-analysis of intervention research. School Psychology Quarterly, 23, 26-42. doi: 10.1037/1045-3830.23.1.26

Mikkelsen, E. G., \& Einarsen, S. (2001). Bullying in Danish working life: Prevalence and Health correlates. European Journal of Work and Organizational Psychology, 4, 393-413. DOI: 10.1080/13594320143000816.

Mikkelsen, E. G., Hogh, A., and Olsen, L. B. (2008). Prevention of bullying and conflicts at work - An intervention study. Proceedings of the $6^{\text {th }}$ International Conference on Workplace bullying, Montréal, Canada (pp. 40-42)

Mitchell, K., Ybarra, M., \& Finkelhor, D. (2007). The relative importance of online victimization in understanding depression, delinquency, and substance use. Child Maltreatment, 12, 314-324. doi:10.1177/1077559507305996

Monks, C., Ortega, R., \& Torrado V. E. (2002). Unjustified aggression in preschool. Aggressive Behavior, 28, 458-476. doi:10.1002/ab.10032

Moore, S. E., Scott, J. G., Thomas, H. J., Sly, P. D., Whitehouse, J. O., Zubrick, S. R., \& Norman, R. E. (2015). Impact of adolescent peer aggression on later educational and 
employment outcomes in an Australian cohort. Journal of Adolescence, 43, 39-49. doi: 10.1016/j.adolescence.2015.05.007

Nansel, T.R., Craig, W., Overpeck, M.D., Salvia, G., \& Ruan, W.J. (2004). Cross- national consistency in the relationship between bullying behaviors and psychosocial adjustment. Archives of Pediatrics and Adolescent Medicine, 158, 730-736. doi: 10.1001/archpedi.158.8.730

Naylor, P., Cowie, H., \& Cossin, F. (2006). Teachers’ and pupils’ definitions of bullying. British Journal of Educational Psychology, 76, 553-576.

Nielsen, M. B., Matthiesen, S. B., \& Einarsen, S. (2010). The impact of methodological moderators on prevalence rates of workplace bullying. A meta-analysis. Journal of Occupational and Organizational Psychology, 83, 955-979. DOI:10.1348/096317909X481256.

Nocentini, A., Calmaestra, J., Schultz-Krumbholz, A., Scheithauer, H., Ortega, R., \& Menesini, E. (2010). Cyberbullying: Labels, behaviors and definition in three European countries. Australian Journal of Guidance and Counselling, 20, 129-142. doi:10.1375/ajgc.20.2.129

Notelaers, G., De Witte, H., \& Einarsen, S. (2010). A job characteristics approach to explain workplace bullying. European Journal of Work and Organizational Psychology, 19, 487504. http://dx.doi.org/10.1080/13594320903007620.

O’Moore, M. (2010). Understanding school bullying: A guide for parents and teachers. Dublin: Venitas.

Osatuke, K., Moore, S. C., Ward, C., Dyrenforth, S. R., \& Belton, L. (2009). Civility, Respect, Engagement in the Workforce (CREW). Nationwide organization development 
intervention at veterans health administration. The Journal of Applied Behavioral Science, 45, 384-410. DOI: 0.1177/0021886309335067.

Parzefall, M-R., \& Salin, D. M. (2010). Perceptions of and reactions to workplace bullying: A social exchange perspective. Human Relations, 63, 761-780. DOI: 10.1177/0018726709345043.

Paull, M., Omari, M., \& Standen, P. (2012). When is a bystander not a bystander? A typology of the roles of bystanders in workplace bullying. Asia Pacific Journal of Human Resources, 50, 351-366. DOI:10.1111/j.1744-7941.2012.00027.x.

Pearson, C. M., Andersson, L. M., \& Porath, C. L. (2005). Workplace Incivility. In S. Fox \& P. E. Spector (Eds.), Counterproductive work behavior. Investigations of actors and targets (pp. 177-200). Washington: American Psychological Association.

PRIMA EF (2008). Best Practice in Workplace Violence and Bullying Interventions. Helsinki, Finland: Author.

Rayner, C., \& Cooper, C. L. (2006). Workplace bullying. In E. K. Kelloway., J. Barling., \& J. J. Hurrell, (Eds.), Handbook of Workplace Violence (pp. 121-145). Thousand Oaks, CA: Sage.

Rayner, C., \& McIvor, K. (2008). Unpublished research report on the Dignity at Work project. Business School, University of Portsmouth (May, 2008).

Resch, M., \& Schubinski, M. (1996). Mobbing - Prevention and management in organizations. European Journal of Work and Organizational Psychology, 5, 295-307. http://dx.doi.org/10.1080/13594329608414860.

Richards, J., \& Daley, H. (2003). Bullying policy: Development, implementation and monitoring. In S. Einarsen, H. Hoel, D. Zapf, and C. L. Cooper (Eds.), Bullying and 
emotional abuse in the workplace. International perspectives in research and practice (pp. 248-258). London, UK: Taylor and Francis.

Rigby. K., \& Bagshaw, D. (2003). Prospects of adolescent students collaborating with teachers in addressing issues of bullying and conflict in schools. Educational Psychology, 23, 535546. doi:10.1080/0144341032000123787

Rigby, K., \& Bauman, S. (2009). How school personnel tackle cases of bullying. In S. Jimerson, S. Swearer, \& D. Espelage (Eds.), Handbook of bullying in schools: An international perspective (pp. 455-467). Hoboken: Routledge.

Rigby, K., \& Johnson, K., (2016). The prevalence and effectiveness of anti-bullying strategies employed in Australian schools. Adelaide: University of South Australia.

Roberge, G. D., 2011. Countering school bullying: An analysis of policy content in Ontario and Saskatchewan. International Journal of Education Policy and Leadership, 6 (5), pp. 1-14.

Saarento, S., Garandeau, C. F., \& Salmivalli, C. (2015). Classroom- and school-level contributions to bullying and victimization: A review. Journal of Community and Applied Social Psychology, 25, 204-218. doi:10.1002/casp.2207

Salin, D. (2001). Prevalence and forms of workplace bullying among business professionals: A comparison of two different strategies for measuring bullying. European Journal of Work and Organizational Psychology, 10, 425-441. DOI: 10.1080/13594320143000771.

Salin, D. (2003). Ways of explaining workplace bullying: A review of enabling, motivating and precipitating structures and processes in the work environment. Human Relations, 56, 1213-1232. DOI: 0018-7267(200310)56:10.

Salin, D. (2008). The prevention of workplace bullying as a question of human resource management: Measures adopted and underlying organizational factors. Scandinavian Journal of Management, 24, 221-231. DOI:10.1016/j.scaman.2008.04.004. 
Samara, M., \& Smith, P. K. (2008). How schools tackle bullying, and the use of whole school policies: Changes over the last decade. Educational Psychology, 28, 663- 676. doi: $10.1080 / 01443410802191910$

Saunders, P., Huynh, A., \& Goodman-Delahunty, J. (2007). Defining workplace bullying behavior professional lay definitions of workplace bullying. International Journal of Law and Psychiatry, 30, 340-354. http://dx.doi.org/10.1016/j.ijlp.2007.06.007.

Scheufele, D. A., \& Tewksbury, D. (2007). Framing, agenda setting, and priming: The evolution of three media effects models. Journal of Communication, 57, 9-20. doi:10.1111/j.14602466.2006.00326.X

Schissell, B. (1997). Blaming children: Youth crime, moral panics and the politics of hate. Halifax: Fernwood.

Scully, M., \& Rowe, M. (2009). Bystander training within organizations. Journal of the International Ombudsman Association, 2, 1-9.

Seigne, E., Coyne, I., Randall, P., \& Parker, J. (2007). Personality traits of bullies as a contributory factor in workplace bullying. An exploratory study. International Journal of Organization Theory and Behavior, 10, 118-132.

Skogstad, A., Matthiesen, S. B., \& Einarsen, S. (2007). Organizational changes: A precursor of bullying at work? International Journal of Organizational Theory and Behavior, 10, 5894.

Smith, P. K. (2011). Why interventions to reduce bullying and violence in school may (or may not) succeed: Comments on the special section. International Journal of Behavioral Development, 35, 419-423. doi:10.1177/0165025411407459

Smith, P.K., Ananiadou, K., \& Cowie, H. (2003). Interventions to reduce school bullying. Canadian Journal of Psychiatry, 48, 591-599. doi:10.1177/070674370304800905 
Smith, P. K., Mahdavi, J., Carvalho, M., Fisher, S., Russell, S., \& Tippett, N. (2008).

Cyberbullying: Its nature and impact in secondary school pupils. The Journal of Child Psychology and Psychiatry, 49, 376-385. doi: 10.111/j.1469-7610.2007.01846.x

Smith, P. K., \& Slonje, R. (2010). Cyberbullying: The nature and extent of a new kind of bullying, in and out of school. In S. R. Jimerson, S. M. Swearer, \& D. Espelage (Eds.), Handbook of bullying in schools: An international perspective (pp. 249-262). New York: Routledge.

Snakenbourg, J., Van Acker, R., \& Gable, R. A. (2011). Cyberbullying: Prevention and intervention to protect our children and youth. Preventing School Failure, 55(2), 88-95. doi:10.1080/1045988X.2011.539454

Souter, A., \& McKenzie, A. (2000). The use and effects of anti-bullying and anti-harassment policies in Australian schools. School Psychology International, 21, 96-105. doi:10.1177/0143034300211007

Spears, B.A., Campbell, M.A., Tangen, D., Slee, P.T., \& Cross, D. (2015). Bridging the gap of school change: Pre-service teachers' knowledge and understanding of cyberbullying. Special Edition: Dossiers des Sciences de l'Education, 33, 109-130.

Spears, B., Slee, P., Owens, L., \& Johnson, B. (2009). Behind the scenes and screens: Insights into the human dimension of covert and cyberbullying. Journal of Psychology, 217(4), 189-196. doi:10.1027/0044-3409.217.4.189

Spurgeon, A. (2003). Bullying from a risk management perspective. In S. Einarsen, H. Hoel, D. Zapf, and C. L. Cooper (Eds.), Bullying and emotional abuse in the workplace. International perspectives in research and practice (pp. 327-338). London, UK: Taylor and Francis. 
Sticca, F., Ruggieri, S., Alsaker, F., \& Perren, S. (2013). Longitudinal risk factors for cyberbullying in adolescence. Journal of Community and Applied Social Psychology, 23, 52-67. doi:10.1002/casp.2136

Surdin, A. (2009, January 1). In several states, a push to stem cyber-bullying: Most of the laws focus on schools. The Washington Post.

Swearer, S., \& Givens, J. E. (2006). Designing an alternative to suspension for middle school bullies. Paper presented at the annual convention of the National Association of School Psychologists, Anaheim, CA.

Tehrani, N. (2003). Counselling and rehabilitating employees involved with bullying. In S. Einarsen, H. Hoel, D. Zapf, and C. L. Cooper (Eds.), Bullying and emotional abuse in the workplace. International perspectives in research and practice (pp. 270-284). London, UK: Taylor and Francis.

Tehrani, N. (2012). An integrated counselling approach. In N. Tehrani, (Ed.), Workplace Bullying. Symptoms and Solutions (pp. 149-164). East Sussex: Routledge

Tepper, B. J. (2000). Consequences of abusive supervision. Academy of Management Journal, 43, 178-190. DOI: 10.2307/1556375.

Thomas, H. J., Chan, G., Scott, J., Connor, J., Kelly, A., \& Williams, J. (2016). Association of different forms of bullying victimisation with adolescents' psychological distress and reduced emotional wellbeing. Australian and New Zealand Journal of Psychiatry, 50, 371-379. doi: 10.1177/0004867415600076

Ttofi, M. M., \& Farrington, D. P. (2011). Effectiveness of school-based programs to reduce bullying: A systematic and analytic review. Journal of Experimental Criminology, 7, 2756. doi: 10.1007/s11292-010-9109-1 
Ttofi, M. M., Farrington, D. P., \& Lösel, F. (2011). Do the victims of school bullies tend to become depressed later in life? A systematic review and meta-analysis of longitudinal studies. Journal of Aggression, Conflict and Peace Research, 3, 63-73. doi:10.1108/17596591111132873

Unnever, J. D. (2005). Bullies, aggressive victims, and victims: Are they distinct groups? Aggressive Behavior, 31, 153-171. doi: 10.1177/08862605022338731

Vago, S. (2009). Law and society. New Jersey: Pearson Prentice-Hall.

Vandebosch, H., Simulioniene, R., Marczak, M., Vermeulen, A., \& Bonetti, L. (2013). The role of the media. In P. K. Smith \& G. Steffgen (2013). Cyberbullying through the new media: Findings from an international network (pp. 99-118). London: Psychology Press.

Vartia, M., Korppoo, L., Fallenius, S., \& Mattila, M. (2003). Workplace bullying: The role of occupational health services. In S. Einarsen, H. Hoel, D. Zapf, and C. L. Cooper (Eds.), Bullying and emotional abuse in the workplace. International perspectives in research and practice (pp. 285-298). London, UK: Taylor and Francis.

Vartia, M., \& Leka, S. (2011). Interventions for the prevention and management of bullying at work. In S. Einarsen, H. Hoel, D. Zapf, \& C. L. Cooper (Eds.), Bullying and harassment in the workplace. Developments in theory, research and practice (pp. 359-380). Boca Raton, FL: CRC Press.

Walton, G. (2005). Bullying widespread: A critical analysis of research and public discourse on bullying. Journal of School Violence, 4, 91-118. doi: 10.1300/J202v04n01_06

Wang, C., Berry, B., \& Swearer, S. M. (2013). The critical role of school climate in effective bullying prevention. Theory and Practice, 52, 296-302. doi:

$10.1080 / 00405841.2013 .829735$ 
Wolke, D., Copeland, W., Angold, A., \& Costello, J. (2013). Impact of bullying in childhood on adult health, wealth, crime and social outcomes. Psychological Science, 24, 1958-1970. doi: 10.1177/0956797613/i81608

Woodman, P., \& Cook, P. (2005). Bullying at work. The experience of managers. London, UK: Chartered Management Institute.

Woodman, P., \& Kumar, V. (2008). Bullying at work 2008. The experience of managers, London, UK: Chartered Management Institute.

Woods, S., \& Wolke, D. (2003). Does the content of anti-bullying policies inform us about the prevalence of direct and relations bullying behavior in primary schools? Educational Psychology, 23, 381-401. doi:10.1080/01443410303215

Yamada, D. (2011). Workplace bullying and the law: Emerging global responses. In S. Einarsen, H. Hoel, D. Zapf, \& C. L. Cooper (Eds.), Bullying and harassment in the workplace. Developments in theory, research and practice (pp. 469-484). Boca Raton, FL: CRC Press.

Ybarra, M. L., Boyd, D., Korchmaros, J., \& Oppenheim, J. (2012). Defining and measuring cyberbullying within the larger context of bullying victimization. Journal of Adolescent Health, 51, 53-58. doi: 10.1016/j.jadohealth.2011,12,031

Yeager, D. S., Fong, C. J., Lee, H., \& Espelage, D. (2015). Declines in efficacy of anti-bullying programs among older adolescents: A developmental theory and a three-level metaanalysis. Journal of Applied Developmental Psychology, 37, 36-51. doi:

10.1016/j.appdev.2014.11.005

Yeager, D., Johnson, R., Spitzer, B., Trzesniewski, K., Powers, J., \& Dweck, C. (2014). The farreaching effects of believing people can change: Implicit theories of personality shape 
stress, health, and achievement during adolescence. Journal of Personality and Social Psychology, 106, 867-884. doi:10.1037/a0036335

Zapf, D., \& Einarsen, S. (2001). Bullying in the workplace: Recent trends in research and practice - an introduction. European Journal of Work and Organizational Psychology, 10, 369-373. DOI: 10.1080/13594320143000807. 
Table 1.

Contingency model of conflict interventions based on Keashly and Nowell (2011).

\begin{tabular}{lll}
\hline Stage & Features & Intervention \\
\hline Discussion & $\begin{array}{l}\text { Ensure accurate communication } \\
\text { and perceptions }\end{array}$ & $\begin{array}{l}\text { Conciliation approach to assist } \\
\text { communication ultimately resulting } \\
\text { in negotiation. }\end{array}$ \\
Polarization & $\begin{array}{l}\text { Trust and respect are under threat } \\
\text { and relationships are central }\end{array}$ & $\begin{array}{l}\text { Consultation to resolve relationship } \\
\text { issues and a move to mediation once } \\
\text { issues have been resolved. }\end{array}$ \\
Segregation & Competition and hostility & $\begin{array}{l}\text { Arbitration or power mediation to } \\
\text { gain control and halt escalation. }\end{array}$ \\
Destruction & $\begin{array}{l}\text { Intention to harm and destroy the } \\
\text { other person }\end{array}$ & $\begin{array}{l}\text { Peacekeeping via forcefully setting } \\
\text { norms and isolating individuals. }\end{array}$ \\
\hline
\end{tabular}

